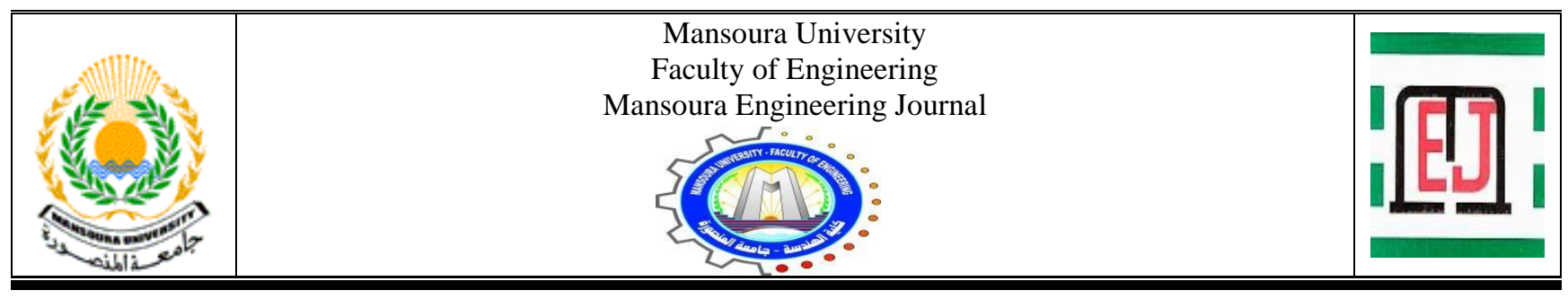

\title{
Prediction of characteristic strength of sustainable concrete containing mineral additives by artificial neural networks
}

\author{
Mohamed S. Elgamal, Ahmed M. Tahwia and Ashraf Heniegal
}

\begin{tabular}{|lr|}
\hline \multicolumn{2}{|l|}{ KEYWORDS: } \\
Artificial & neural \\
network, & sustainable \\
concrete, & characteristic \\
strength, & pozzolanic \\
materials. & \\
& \\
& \\
\end{tabular}

Abstract - It this study, the application of artificial neural networks (ANN) for estimating the characteristic strength of sustainable concrete that contains various amounts of fly ash, silica fume, slag and steel fiber have been investigated. Using ANN model, it is possible to establish a linear and nonlinear correlation between known input data like concrete ingredients and a certain output like characteristic strength, because $A N N$ is an excellent tool to determine concrete properties. For the training of ANN models, an experimental data base (1410 concrete mixtures from earlier published papers) has been utilized. Then experimental tests were performed on some mixes of concrete to validate the model. The ANN model parameter statistics $R^{r}$ is $0.888,0.93,0.9$ for training, validation and test steps and indicate that $A N N$ model makes effective prediction for characteristic strength of sustainable concrete. The application of ANN in predicting characteristic strength is considered to the quality assurance of manufacturing of concrete.

\section{INTRODUCTION}

$\mathrm{T}$ HE actual concrete market is highly competitive these days. The companies are saving the budget, so they need to enter technology and their tests in concrete industry. There are empirical equations for estimating the characteristic strength of concrete based only on concrete tests for normal concrete, so it is important to find out the relationship between concrete and how to predict the strength from concrete mixture in this study.

Received: (06 November, 2020) - Revised: (26 February, 2021) Accepted: (27 March, 2021)

Corresponding Author: Mohamed S. Elgamal, Master of science researcher, Structural Engineering Department, Mansoura University, Mansoura, Egypt.(e-mail: m.salamaelgamal@gmail.com)

Ahmed M. Tahwia, Professor, Structural Engineering Department, Mansoura University, Mansoura, Egypt.(e-mail: atahwia@mans.edu.eg )

Ashraf Heniegal, Professor, Civil Engineering Department, Suez University, Suez, Egypt. (e-mail: Ashraf.heneagal@suezuni.edu.eg)
An ANN is an artificial intelligence program, which has been used widely in many engineering fields. ANN has the ability to learn to improve its efficiency from inputs and outputs, and to gain knowledge by learning. Hidden layer is connected by weights to other layers, allowing neural network to be trained to perform a specific task by changing the weight values.

ANN requires three distinct steps: preparation, validation and testing. In the training step: the epochs are repeated as long as they do not get into the precision of the desired performance. During the training step the validation step errors are monitored. The test set error is the one that used to compare various models, ANN used in different engineering applications because it establishes relationships between parameters of input and output to give approximate results, [']. A total of $90 \mathrm{mix}$ of concrete were built using the principle of central composite design (CCD) and tested experimentally using MATLAB, the artificial neural network (ANN). Variance test study (ANOVA) was used to evaluate the mathematical models. Analysis indicate that with the rise 
in FA percentage, new SCC features improve while the 28-day strength reduces. [2]

This has been carried out today in many civil engineering problems with some degree of success, such as structural damage determination, structural system determination, material behavior modeling, structural optimization, structural control, groundwater monitoring, prediction of shallow foundation settlement, concrete mixing components, and prediction of typical concrete properties and high performance [3],[4]. Ozcan et al. [5] predicted long-term characteristic strength of silica fume concrete using neural networks. Topcu and Saridemir[3] estimated aerated concrete aggregate properties of autoclaved waste by artificial neural networks. Saridemir[6] investigated the use of neural networks to develop a methodology for predicting concrete characteristic strength with different water -to- cement ratios. Authors put the data used in the model of the neural network into a format of five input parameters covering water-to-cementing ratio, binder sand ratio, percentage of metakaolin, percentage of superplasticizers and age.[7], Three equations were structured to join three known parameters using the multi regression analysis program (Graph pad): (characteristic strength, cement content and workability) with three key unknown ingredients (water, cement and aggregates). [8]

Supplementary cementing materials (SCMs) in the concrete practice is raised nowadays, either in blended cement or as separate supplements into the concrete mixture. Extensive data shows that using pozzolanic materials, reducing the carbon dioxide emissions, which resulted from Portland clinker production. Also, provides a means to become a more sustainable binder for the building industry. Moreover, the utilization of by-product materials involves advantages identified with costs and sustainability aspects. In the last decade, several studies carried out on the SCM effect on microstructure and strength [9]. The SCMs identified include the most commonly used ones, like silica fume, slag cement, fly ash and metakaolin, but also others that may not have attracted as much attention but nevertheless show promise for use in concrete.

Most of the previous published papers discussed prediction of characteristic strength for normal concrete, but in this study the characteristic strength of sustainable concrete containing minerals additives was estimated.

\section{EXPERIMENTAL PROGRAM:}

The experiments were applied using ready-mix concrete in the Egyptian market, designing mix proportion in cubic samples of dimensions $150 \times 150 \times 150 \mathrm{~mm}$ in laboratory. The characteristics of materials used as follows:

Cement: Portland cement with grade 42.5 manufactured in the suez cement factories in Egypt. Cement has a specific gravity of 3.15 .

The blaine specific surface area was $3500 \mathrm{~cm}^{2} / \mathrm{gm}$, with 110 and $280 \mathrm{~min}$ for the initial and final setting times. The cement follows Egyptian requirements (ES 4756:1-2013).
Fine aggregate: In this research, natural fine and clean sand with a modulus of fineness of 2.88 and specific gravity of 2.56 was used. The sand used follows Egyptian standard (ES 1109:2008).

Coarse aggregate: Local crushed dolomite 4/20 mm was used in this study, obtained from Ataka quarry in Suez. The dolomite used is given a specific gravity of 2.63. It conforms to Egyptian standard (ES 1109:2008).

Superplasticizer: A superplasticizer based on polycarboxylate, which is commercially available was used in the mixtures.

Blast furnace slag (BFS): BFS is a by-product made in iron manufacturing. BFS is used to substitute a portion of cement in the mixture and to improve concrete characteristics. The average area of the blaine surface was $5000 \mathrm{~cm}^{2} / \mathrm{gm}$, and its specific gravity was 2.9 .

Steel fiber: Added to improve the structural properties, especially tensile, and help to control cracking flexural resistance, with discrete lengths of steel fibers with an aspect ratio (Length to diameter ratio) of about 10 to 100.Steel fibers are fabricated from a low carbon steel and conformance physical property requirements of ASTM A820.

Water: Water is clean, free of any harmful matter, and taken out of a public use.

Fly ash: This is a waste material from a thermal power plant with a fixed gravity of $2.3 \mathrm{t} / \mathrm{m}^{3}$. According to ASTM C618 the used FA was class $\mathrm{C}$ and F. Used in concrete mixtures as a mineral additive and usually graded in Class $\mathrm{C}$ and F.

Silica fume: This is an ultrafine powder obtained as a byproduct and waste material for the manufacture of silicone and ferrosilicone. It was purchased from Ferro Alloys Company of Egypt (EFACO). Silica is made up of spherical particles with a mean particle diameter of $120 \mathrm{~nm}$ and a specific gravity of $2.25 \mathrm{t} / \mathrm{m}^{3}$.

\section{A. Layout research:}

1. Part one: a total of 1410 data sets were gathered from experiments performed from published papers, then by Matlab software made a model on neural networks.

2. Part two: perform an experimental characteristic strength test on concrete cubes to allow validation and test on the model.

\section{B. Specimen production:}

1. The specimens were casted in high quality concrete lab .

2. The concrete came from ready-mix concrete stations with various designs for mixing and already used in the field .

3. The molds were used $150 \times 150 \times 150 \mathrm{~mm}$ cubes and casted in 3 layers, each layer compacted twenty-five times according to standard ASTM C31, then held in the air for a day to be set properly and then put concrete out of the mold and healing water tank at the correct temperature .

4. The samples are taken out of the curing tank after the specific healing time and sometimes kept in the air so that the surface is dried. 
- The curing was carried out by immersing the samples in the water tank according to ASTM C31 with temperature in the field according to ASTM C1064.

\section{DATA PREPARATION}

In this study, a total of 1410 data sets were collected from experiments performed from published papers [10-32].

The data were divided into ten inputs and one outputs as following:

Inputs are: The concrete components (cement, fine aggregate, coarse aggregate, fly ash, silica fume, blast furnace slag, steel fiber, water and superplasticizer) and age of concrete specimens.

Outputs are: The concrete characteristic strength.

These data are divided into $70 \%$ for training, $15 \%$ for validation and $15 \%$ for testing.

TABLE 1

A SAMPLE FROM THE COLLECTED DATA

\begin{tabular}{|c|c|c|c|c|c|c|c|c|c|c|}
\hline \multicolumn{10}{|c|}{ Inputs } & \multirow{3}{*}{$\begin{array}{l}\text { Outputs } \\
\text { F }_{\text {cu }} \\
\text { (MPa) }\end{array}$} \\
\hline \multicolumn{9}{|c|}{ Components (Kg) } & \multirow{2}{*}{$\begin{array}{l}\begin{array}{l}\text { Age } \\
\text { (day) }\end{array}\end{array}$} & \\
\hline PC & $F_{\text {agg }}$ & $\mathrm{C}_{\mathrm{agg}}$ & FA & SF & BFS & St & $\mathbf{W}$ & SP & & \\
\hline 240 & 681 & 1021 & 30 & 0 & 30 & 0 & 90 & 0 & 3 & 15 \\
\hline 210 & 681 & 1021 & 60 & 0 & 30 & 0 & 90 & 0 & 3 & 16 \\
\hline 180 & 681 & 1021 & 90 & 0 & 30 & 0 & 90 & 0 & 3 & 13 \\
\hline 150 & 681 & 1021 & 120 & 0 & 30 & 0 & 90 & 0 & 3 & 16 \\
\hline 450 & 582 & 1163 & 0 & 27 & 0 & 0 & 158 & 8 & 7 & 41 \\
\hline 800 & 1050 & 0 & 0 & 800 & 0 & 80 & 170 & 40 & 28 & 19 \\
\hline 240 & 681 & 1021 & 0 & 0 & 60 & 0 & 90 & 0 & 3 & 11 \\
\hline 350 & 665 & 1332 & 0 & 0 & 0 & 0 & 175 & 0 & 7 & 16 \\
\hline 425 & 606 & 1211 & 0 & 0 & 0 & 0 & 157 & 0 & 28 & 43 \\
\hline 350 & 610 & 1240 & 0 & 0 & 0 & 0 & 220 & 0 & 28 & 24 \\
\hline 300 & 511 & 1191 & 0 & 0 & 0 & 0 & 75 & 0 & 3 & 7 \\
\hline 300 & 681 & 1021 & 0 & 0 & 0 & 0 & 90 & 0 & 3 & 30 \\
\hline 200 & 511 & 1191 & 0 & 0 & 0 & 0 & 60 & 0 & 7 & 9 \\
\hline 300 & 340 & 1362 & 0 & 0 & 0 & 0 & 90 & 0 & 90 & 18 \\
\hline 400 & 511 & 1191 & 0 & 0 & 0 & 0 & 120 & 0 & 180 & 21 \\
\hline
\end{tabular}

Where: PC: cement, Fagg: fine aggregate, Cagg: course aggregate, FA: fly ash, SF: silica fume, BFS: blast furnace slag, St: steel fiber, W: water, SP: superplasticizer, Fcu: characteristic strength.

TABLE 2

THE RANGES AND AVERAGE VALUES FOR DATA SETS

\begin{tabular}{l||l||l} 
Variables & Range (Min-Max) & Average \\
\hline$X_{1}($ Cement $) \mathrm{kg}$ & $120-800$ & 283 \\
\hline$X_{2}$ (Fine aggregate) $\mathrm{kg}$ & $222-1000$ & 669 \\
\hline$X_{3}$ (Coarse aggregate) $\mathrm{kg}$ & $0-1916$ & 1081 \\
\hline$X_{4}($ Fly ash) $\mathrm{kg}$ & $0-180$ & 32 \\
\hline$X_{5}($ Silica fume) $\mathrm{kg}$ & $0-200$ & 2 \\
\hline$X_{6}($ BFS $) \mathrm{kg}$ & $0-180$ & 23 \\
\hline$X_{7}($ St $) \mathrm{kg}$ & $0-80$ & 1 \\
\hline$X_{8}($ Water $) \mathrm{kg}$ & $60-269$ & 115 \\
\hline$X_{9}($ Superplasticizer $) \mathrm{kg}$ & $0-40$ & 1 \\
\hline$X_{10}$ (Age) day & $1-180$ & 53 \\
\hline$Y_{1}($ characteristic strength) $\mathrm{MPa}$ & $7-68$ & 26
\end{tabular}

Where: $X_{n}$ : is the inputs, $Y_{n}$ : is the outputs

After gathered the data, all input data have been normalized to be in the range (0-1) using this formula:

The new data in every cell

$$
=\frac{\text { Feature }-\min (\text { feature })}{\max (\text { feature })-\min (\text { feature })}
$$

Where: the feature is the data before normalization.

\section{MODEL APPLICATION}

The network contains inputs, hidden layers and outputs. Characteristic strength is the output while the input layer contains 10 nodes representing the age of concrete specimens and concrete components (cement, fine agg, coarse agg, fly ash, silica fume, blast furnace slag, steel fiber, water and superplasticizer). The hidden layer included 6 nodes, and a full connection between the nodes in the adjacent layers.

1. Type of neural network: Multilayer perceptron feedforward was trained through the error back-propagation algorithm.

2. Neurons in the input layer: ten neurons.

3. Hidden layers: it has been found that a single hidden layer presents satisfactory results for many problems.[5]

4. Neurons in hidden layer: Six neurons were specified from empirical criteria.

5. Neurons in the output layer: one neurons.

6.

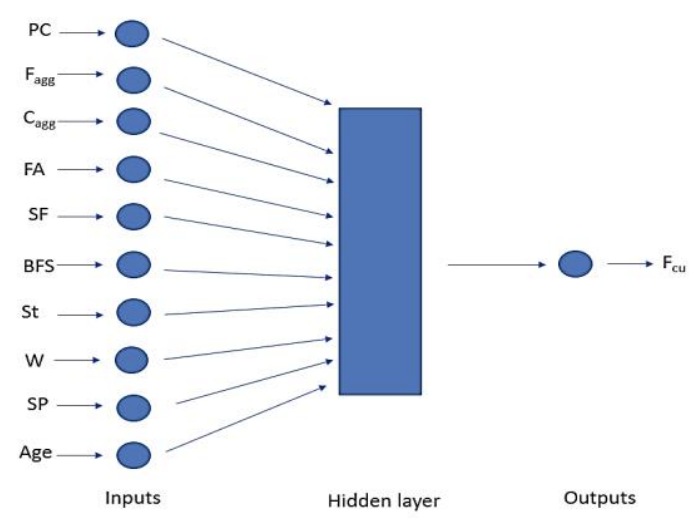

Fig 1: Structure of ANN model.

The model passes with three phases: training, validation and testing. In the training procedure we calculate the mean square error (MSE) and then back propagated to the network. Biases and weights of the connection strength between nodes are modified during the back-propagation phase such that the (MSE) are reduced, [33]

TABLE 3

MODEL COMPONENTS

\begin{tabular}{l} 
Neurons in the input layer: 10 neurons \\
\hline Neurons in the hidden layer: 6 neurons \\
\hline Neurons in the output layer: 1 neurons \\
\hline Activation function used: tansig \\
\hline Type of backpropagation algorithm: trainlm
\end{tabular}

As shown in table 3: we choose Levenberg-Marquardt (trainlm) because Levenberg-Marquardt showed the capability of achieving the most optimum prediction.

\section{RESULTS AND DISCUSSION}

- Many iterations have had and chosen the best iteration using the least MSE.

- The iterations were done using various inputs of layers and neurons, and the best values is 2 layers and 6 neurons. 


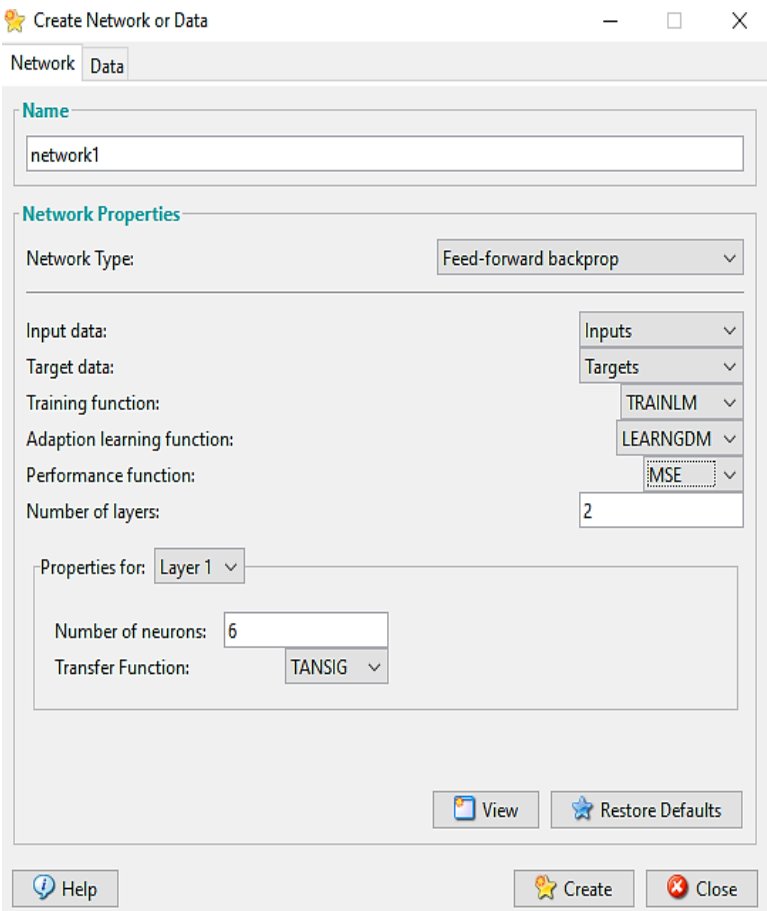

Fig 2: Creating ANN network

Figure 2 presents the training state for ANN model and shows the errors are repeated 6 after epoch 0 And the test stopped at epoch 6 .

The epoch 0 is selected as the base and its weights are chosen as the final weights. So the validation check is equal to 6 , due to the fact that the errors are repeated 6 times before stopping the process.

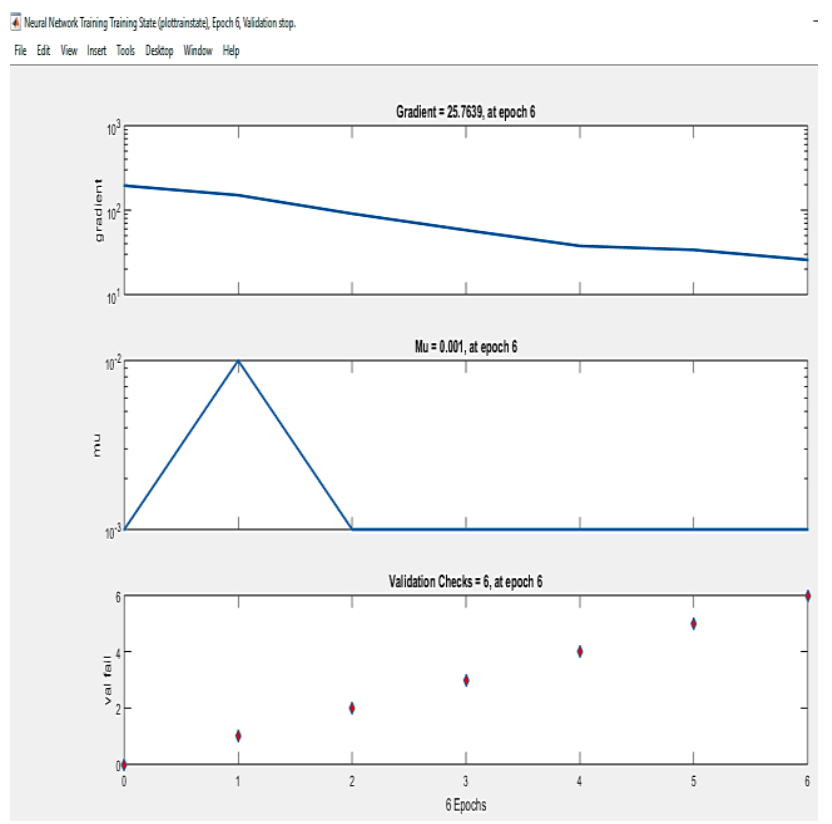

Fig. 3: The training state for ANN model.

Figure 4 provids the best validation performance and mean square error (MSE) of the network start at a large value and then reducing to a small value. The chart consists of three lines for training, validation, and test. Training continues until the model gets to the point that the training reduces the error of network on the validation. As shown in figure, the best validation performance is happened at epoch 0 after 6 error repeated.

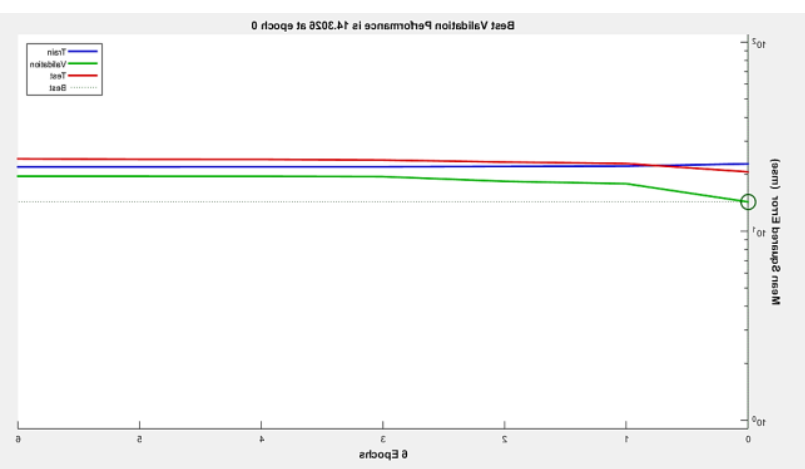

Fig. 4: The best validation performance and mean square error (MSE).

Figures 5, 6, 7 show the coincidence between the output and target variables for training, validation and test steps. The output values imply the predicted characteristic strength by matlab software and the target values imply the measured characteristic strength. The term " $\mathrm{R}^{2}$ " is calculated by matlab software which demonstrates the model efficiency and so the $\mathrm{R}^{2}$ values in the three figures confirms acceptable accuracies of the model in the training, validation and test.

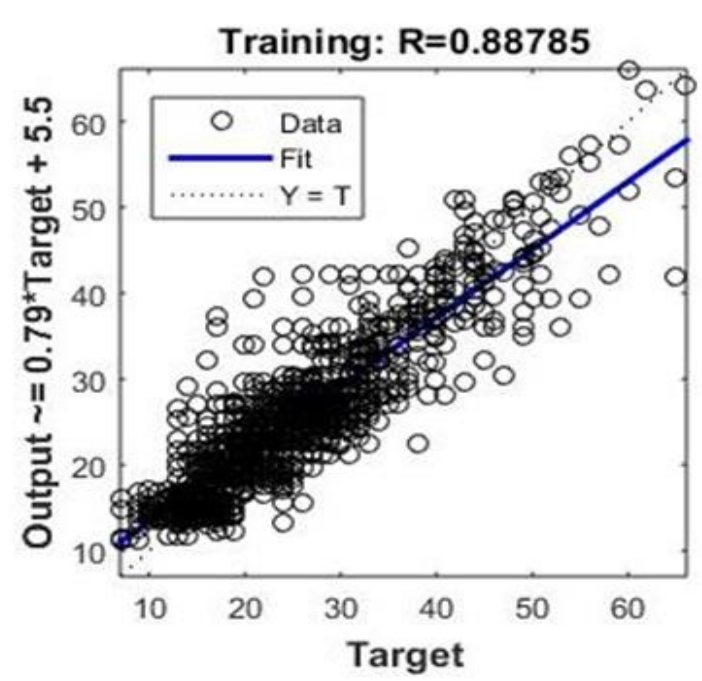

Fig. 5: The coincidence between the output and target variables for training for model 1. 


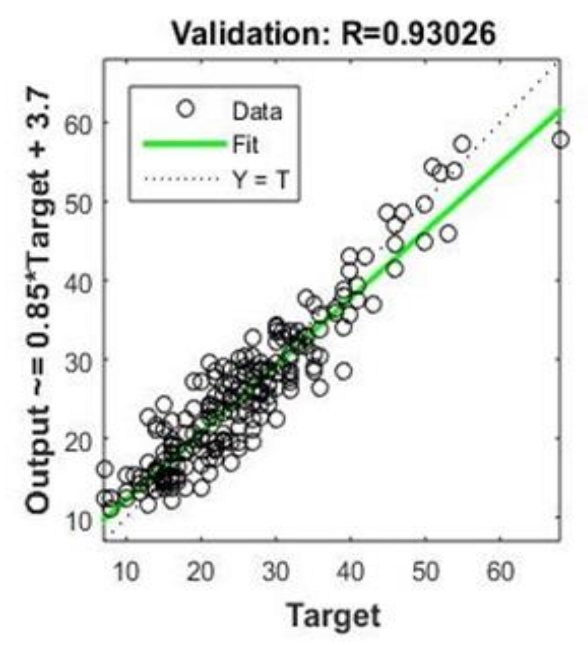

Fig. 6: The coincidence between the output and target variables for validation for model 1.

As shown in the test figure, the term $\mathrm{R}^{2}=0.9$ which implies efficiency of the model in predicting (the characteristic strength, RN, UPV) and contain the nonlinear relation between the input variables.

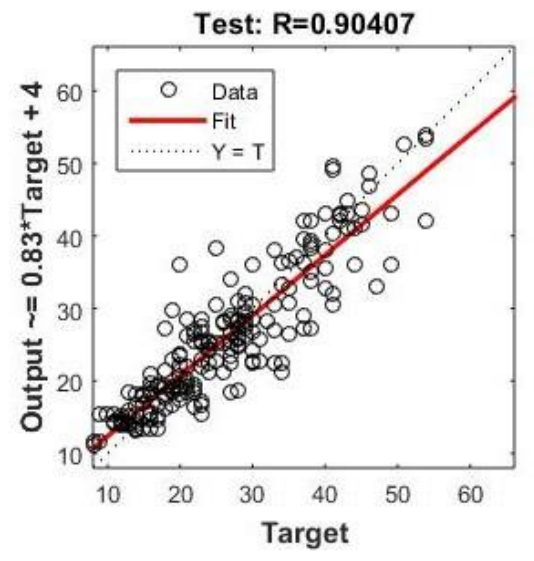

Fig. 7: The coincidence between the output and target variables for test steps.

To test the ANN model accuracy, a total of 13 concrete mixtures were made with minerals additives of FA, SF and BFS and presented from actual ready-mix concrete and tested in the concrete lab and entered the results to the ANN model and the network predict characteristic strength for each mixture. The inputs (mix components and the age) are listed in table 4 , and the measured and predicted output values are listed in table 5.

TABLE 4

THE TESTED INPUTS (CONCRETE COMPONENT AND AGE).

\begin{tabular}{|c|c|c|c|c|c|c|c|c|c|c|}
\hline \multirow{3}{*}{$\begin{array}{l}\text { Mix } \\
\text { No. }\end{array}$} & \multicolumn{9}{|c|}{ Inputs } & \multirow{3}{*}{$\begin{array}{c}\text { Age } \\
\text { (day) }\end{array}$} \\
\hline & \multicolumn{8}{|c|}{ Components (Kg) } & \multirow[b]{2}{*}{ SP } & \\
\hline & PC & $\mathbf{F}_{\text {agg }}$ & $\mathbf{C}_{\text {agg }}$ & FA & SF & BFS & St & $\mathbf{W}$ & & \\
\hline 1 & 450 & 650 & 1150 & 0 & 0 & 0 & 0 & 160 & 9 & 28 \\
\hline 2 & 225 & 650 & 1150 & 112.5 & 0 & 112.5 & 0 & 160 & 9 & 28 \\
\hline 3 & 225 & 650 & 1150 & 135 & 67.5 & 22.5 & 0 & 160 & 9 & 28 \\
\hline 4 & 225 & 650 & 1150 & 22.5 & 67.5 & 135 & 0 & 160 & 9 & 28 \\
\hline 5 & 225 & 650 & 1150 & 90 & 67.5 & 67.5 & 0 & 160 & 9 & 28 \\
\hline 6 & 225 & 650 & 1150 & 67.5 & 67.5 & 90 & 0 & 160 & 9 & 28 \\
\hline 7 & 225 & 717.5 & 1150 & 135 & 0 & 22.5 & 0 & 160 & 9 & 28 \\
\hline 8 & 225 & 717.5 & 1150 & 22.5 & 0 & 135 & 0 & 160 & 9 & 28 \\
\hline 9 & 225 & 717.5 & 1150 & 90 & 0 & 67.5 & 0 & 160 & 9 & 28 \\
\hline 10 & 225 & 717.5 & 1150 & 67.5 & 0 & 90 & 0 & 160 & 9 & 28 \\
\hline 11 & 225 & 672.5 & 1150 & 67.5 & 67.5 & 67.5 & 0 & 160 & 9 & 28 \\
\hline 12 & 225 & 717.5 & 1150 & 67.5 & 22.5 & 67.5 & 0 & 160 & 9 & 28 \\
\hline 13 & 225 & 695 & 1150 & 67.5 & 45 & 67.5 & 0 & 160 & 9 & 28 \\
\hline
\end{tabular}

Table 5

Where: PC: cement, $\mathrm{F}_{\mathrm{agg}}$ : fine aggregate, $\mathrm{C}_{\mathrm{agg}}$ : coarse aggregate, FA: fly ash, SF: silica fume, BFS: blast furnace slag, St: steel fiber, W: water, SP: superplasticizer.

\begin{tabular}{|c|c|c|}
\hline & $\begin{array}{l}\text { Experimental } \\
\text { results }\end{array}$ & Predicted results \\
\hline Mix No. & $\begin{array}{c}\mathbf{F}_{\mathrm{cu}} \\
(\mathbf{M P a})\end{array}$ & $\begin{array}{c}\mathbf{F}_{\mathrm{cu}} \\
(\mathrm{MPa})\end{array}$ \\
\hline 1 & 80 & 52.3 \\
\hline 2 & 70 & 64.8 \\
\hline 3 & 75 & 33.9 \\
\hline 4 & 66 & 65.5 \\
\hline 5 & 77 & 50.5 \\
\hline 6 & 73 & 58 \\
\hline 7 & 55 & 35 \\
\hline 8 & 55 & 65.9 \\
\hline 9 & 57 & 55.8 \\
\hline 10 & 65 & 61.8 \\
\hline 11 & 85 & 46.53 \\
\hline 12 & 73 & 50.8 \\
\hline 13 & 78 & 48.1 \\
\hline
\end{tabular}

Where: $\mathrm{F}_{\mathrm{cu}}$ : characteristic strength. 


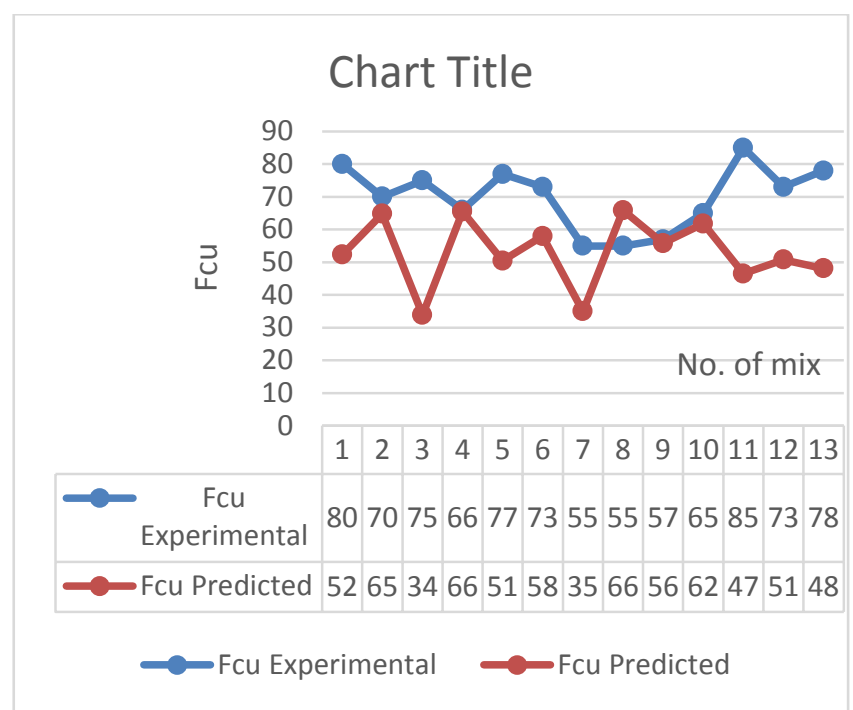

Fig. 8: Chart between Fcu experimental and Fcu predicted with the same concrete mix

\section{CONCLUSION AND RECOMENDATIONS}

A total of 1410 data set were gathered for concrete mixtures from previous published papers at various curing times and test ages are 3, 7, 28,90,180 days and develop

a model on neural networks by MATLAB program with ten inputs and one output, then make an experimental test on concrete and get cubes characteristic strength to make validation and testing on the model.

1. ANN model is an accuracy computational model to predict characteristic strength of sustainable concrete (green concrete) which contains pozzolanic materials.

2. ANN model indicates reliable correlation between input and output variables, the parameter statistics $R^{2}$ is 0.888 , 0.93, 0.9 for training, validation and test steps, which imply good accuracy and efficiency use of ANN model, in predicting characteristic strength and demonstrates the capability of a feed-forward back propagation neural network to predict characteristic strength.

3. It is recommended to build new models to decrease zero values of fly ash, silica fume, BFS, steel fiber and superplasticizer to adjust the model and agree with Jain et al.[12]

\section{AUTHORS CONTRIBUTION}

We encourage authors to submit an author statement outlining their individual contributions to the paper using the relevant roles:

1- Conception or design of the work: Mohamed S. Elgamal, Ahmed M. Tahwia, Ashraf Heniegal.

2- Data collection and tools: Mohamed S. Elgamal.

3- Data analysis and interpretation: Mohamed S. Elgamal, Ashraf Heniegal.

4- Funding acquisition: Mohamed S. Elgamal.

5- Investigation: Mohamed S. Elgamal, Ahmed M. Tahwia.
6- Methodology: Mohamed S. Elgamal, Ashraf Heniegal.

7- Project administration: Ahmed M. Tahwia

8- Resources: Mohamed S. Elgamal.

9- Software: Mohamed S. Elgamal.

10- Supervision: Ahmed M. Tahwia and Ashraf Heniegal

11- Drafting the article: Mohamed S. Elgamal

12- Critical revision of the article: Ahmed M. Tahwia, Ashraf Heniegal.

13- Final approval: Ahmed M. Tahwia.

The corresponding author: Mohamed S. Elgamal.

\section{REFERENCES}

[1] K. FAEZEHOSSADAT and J. SAYED MOHAMMADMEHDI, "PREDICTING THE 28 DAYS COMPRESSIVE STRENGTH OF CONCRETE USING ARTIFICIAL NEURAL NETWORK", imanager's Journal on Civil Engineering, vol. 6, no. 2, p. 1, 2016. Available: 10.26634/jce.6.2.5936.

[2] Elemam, W. E., Abdelraheem, A. H., Mahdy, M. G., \& Tahwia, A. M. (2020). Optimizing fresh properties and compressive strength of selfconsolidating concrete. Construction and Building Materials, 249, 118781.

[3] I. Topçu and M. Sarıdemir, "Prediction of properties of waste AAC aggregate concrete using artificial neural network", Computational Materials Science, vol. 41, no. 1, pp. 117-125, 2007. Available: 10.1016/j.commatsci.2007.03.010.

[4] K.S. Pann, T. Yen, C.-W. Tang, T.D. Lin, "New Strength Model Based on Water-Cement Ratio and Capillary Porosity", ACI Materials Journal, vol. 100, no. 4, 2003. Available: 10.14359/12669.

[5] F. Özcan, C. Atiş, O. Karahan, E. Uncuoğlu and H. Tanyildizi, "Comparison of artificial neural network and fuzzy logic models for prediction of long-term compressive strength of silica fume concrete", Advances in Engineering Software, vol. 40, no. 9, pp. 856863, 2009. Available: 10.1016/j.advengsoft.2009.01.005.

[6] M. Saridemir, "Predicting the compressive strength of mortars containing metakaolin by artificial neural networks and fuzzy logic", Advances in Engineering Software, vol. 40, no. 9, pp. 920-927, 2009. Available: 10.1016/j.advengsoft.2008.12.008.

[7] A. Diab, H. Elyamany, A. Abd Elmoaty and A. Shalan, "Prediction of concrete compressive strength due to long term sulfate attack using neural network", Alexandria Engineering Journal, vol. 53, no. 3, pp. 627-642, 2014. Available: 10.1016/j.aej.2014.04.002.

[8] S. I, Zaki "Computation Method for Concrete Mix Design Using Simple Equations" Algeria conference, belide, 2015.

[9] N. De Belie, M. Soutsos and E. Gruyaert, Properties of Fresh and Hardened Concrete Containing Supplementary Cementitious Materials. .

[10] Mohammadreza Hamidian, "Application of Schmidt rebound hammer and ultrasonic pulse velocity techniques for structural health monitoring", Scientific Research and Essays, vol. 7, no. 21, 2012. Available: $10.5897 / \mathrm{sre} 11.1387$.

[11] U. Atici, "Prediction of the strength of mineral admixture concrete using multivariable regression analysis and an artificial neural network", Expert Systems with Applications, vol. 38, no. 8, pp. 96099618, 2011. Available: 10.1016/j.eswa.2011.01.156.

[12] M. Azreen et al., "Prediction of concrete compression strength using ultrasonic pulse velocity", in AIP Conf. Proc. 1704, 2016.

[13] A. Jain, A. Kathuria, A. Kumar, Y. Verma and K. Murari, "Combined Use of Non-Destructive Tests for Assessment of Strength of Concrete in Structure", Procedia Engineering, vol. 54, pp. 241-251, 2013. Available: 10.1016/j.proeng.2013.03.022.

[14] J. Malek, M. Kaouther, " Destructive and non-destructive testing of concrete structures ", Jordan Journal of Civil Engineering, vol. 8, pp. 432-441, 2014.

[15] R. Domingo and S. Hirose, "Correlation Between Concrete Strength and Combined Nondestructive Tests for Concrete Using High-Early Strength Cement", in Sixth Reg. Symp. Infrastruct. Dev., 2009.

[16] B. Mohammed, M. Abdullahi and C. Hoong, "Statistical models for concrete containing wood chipping as partial replacement to fine 
aggregate", Construction and Building Materials, vol. 55, pp. 13-19, 2014. Available: 10.1016/j.conbuildmat.2014.01.021.

[17] M.N. V, R. Balkiminal, C.D. S, G.V. D, T.V. S, "the Use of Combined Non Destructive Testing in the Concrete Strenght Assessment From Laboratory Specimens and Existing Buildings", International Journal of Current Engineering And Scientific Research, vol. 2, pp. 55$59,2015$.

[18] J. Kim and D. Kim, "Application of neural networks for estimation of concrete strength", KSCE Journal of Civil Engineering, vol. 6, no. 4, pp. 429-438, 2002. Available: 10.1007/bf02841997.

[19] [19] K. Amini, M. Jalalpour and N. Delatte, "Advancing concrete strength prediction using non-destructive testing: Development and verification of a generalizable model", Construction and Building Materials, vol. 102 , pp. 762-768, 2016. Available: 10.1016/j.conbuildmat.2015.10.131.

[20] H. Qaswari, "Concrete strength by combined nondestructive methods simply and reliably predicted", Cement and Concrete Research, vol. 30, pp. 739-746, 2000.

[21] S.A. Al-Mishhadani, A.P.D.H.H. Joni, E.M.S. Radhi, "EFFECT OF AGE ON NONDESTRUCTIVE TESTS RESULTS FOR EXISTING CONCRETE", Iraqi Journal for Mechanical and Materials Engineering, vol. 12, pp. 630-646, 2012.

[22] K. Ali-Benyahia, S. Kenai and M. Ghrici, "Correlations between nondestructive and destructive tests of low strength concrete", in XXXVII IAHS World Congress on Housing, Santander, Spain, 2010.

[23] S. Raju and B. Dharmar, "Mechanical Properties of Concrete with Copper Slag and Fly Ash by DT and NDT", Periodica Polytechnica Civil Engineering, pp. 313-322, 2016. Available: 10.3311/ppci.7904.

[24] I. Nash't, H. Saeed and A. Sadoon, "Finding an Unified Relationship between Crushing Strength of Concrete and Non-destructive Tests", in 3rd Middle East NDT Conference and Exhibition, 2005.

[25] U. Na, T. Park, M. Feng and L. Chung, "Neuro-fuzzy application for concrete strength prediction using combined non-destructive tests", Magazine of Concrete Research, vol. 61, no. 4, pp. 245-256, 2009. Available: 10.1680/macr.2007.00127.

[26] T. Soshiroda, K. Voraputhaporn and Y. Nozaki, "Early-stage inspection of concrete quality in structures by combined nondestructive method", Materials and Structures, vol. 39, no. 2, pp. 149-160, 2006. Available: 10.1617/s11527-005-9007-6.

[27] T. Lal, S. Sharma and S. Naval, "Reliability of Non-Destructive Tests for Hardened Concrete Strength", INTERNATIONAL JOURNAL OF ENGINEERING RESEARCH \& TECHNOLOGY, vol. 2, no. 3, pp. 17, 2013. [Accessed 1 November 2020].

[28] J. Bogas, M. Gomes and A. Gomes, "Compressive strength evaluation of structural lightweight concrete by non-destructive ultrasonic pulse velocity method", Ultrasonics, vol. 53, no. 5, pp. 962-972, 2013. Available: 10.1016/j.ultras.2012.12.012.
[29] J. Hoła and K. Schabowicz, "APPLICATION OF ARTIFICIAL NEURAL NETWORKS TO DETERMINE CONCRETE COMPRESSIVE STRENGTH BASED ON NON- DESTRUCTIVE TESTS", JOURNAL OF CIVIL ENGINEERING AND MANAGEMENT, vol. 11, no. 1, pp. 23-32, 2005. Available: 10.3846/13923730.2005.9636329.

[30] B. Hobbs and M. Tchoketch Kebir, "Non-destructive testing techniques for the forensic engineering investigation of reinforced concrete buildings", Forensic Science International, vol. 167, no. 2-3, pp. 167172, 2007. Available: 10.1016/j.forsciint.2006.06.065.

[31] A. Wankhade, M Kambekar, "Prediction of compressive strength of concrete using artificial neural", International Journal of Scientific Research and Reviews, vol. 2, pp. 11-26, 2013.

[32] D. Bzeni and M. Ihsan, "Estimating strength of SCC using nondestructive combined method", in Sustainable Construction Materials and Technologies, 2013.

[33] A. Heniegal, "NUMERICAL ANALYSIS FOR PREDICTING OF SELF COMPACTING CONCRETE MIXTURES USING ARTIFICIAL NEURAL NETWORKS", JES. Journal of Engineering Sciences, vol. 40, no. 6, pp. 1575-1597, 2012. Available: 10.21608/jesaun.2012.114530.

\section{Title Arabic:}

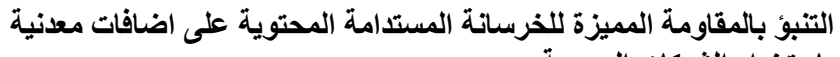
باستخدام الثبكات العصبية.

\section{Arabic Abstract:}

في هذه الدراسة: بإستخدام الشبكات العصبية(ANN)، يتم التتبؤ بالمقاومة

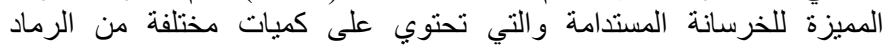

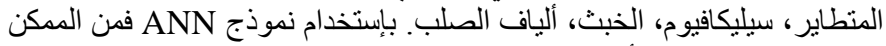

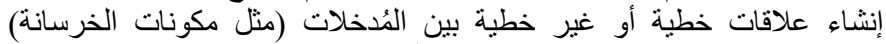
والمُخرجات كـ المقاومة المميزة، وذللك لأن الثبكات العبرة العصبية هي آداة ممتازة لتحديد خو اص الخرساتة

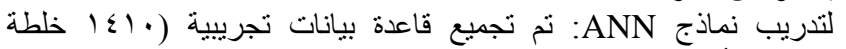

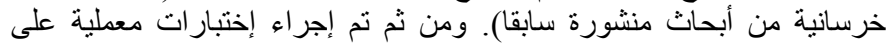
بعض خلطات الخرسانة لإختبار نموذج أبن ANN. R وهي

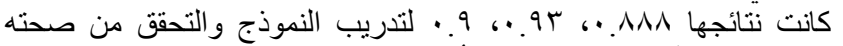

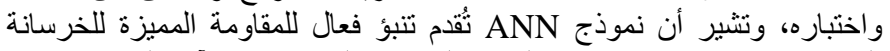

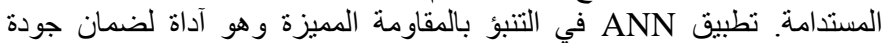
صناعة الخرسانة. 